FACULTY OF ECONOMICS AND APPLIED ECONOMIC SCIENCES

CENTER FOR ECONOMIC STUDIES

ENERGY, TRANSPORT \& ENVIRONMENT

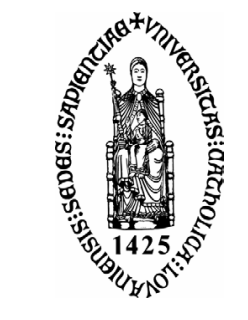

KATHOLIEKE UNIVERSITEIT LEUVEN

WORKING PAPER SERIES

$n^{\circ}$ 2004-10

\title{
Regulating on-street parking
}

\author{
E. Calthrop (CER, Brussels, Belgium) \\ S. Proost (K.U.Leuven - CES; CORE - UCLouvain)
}

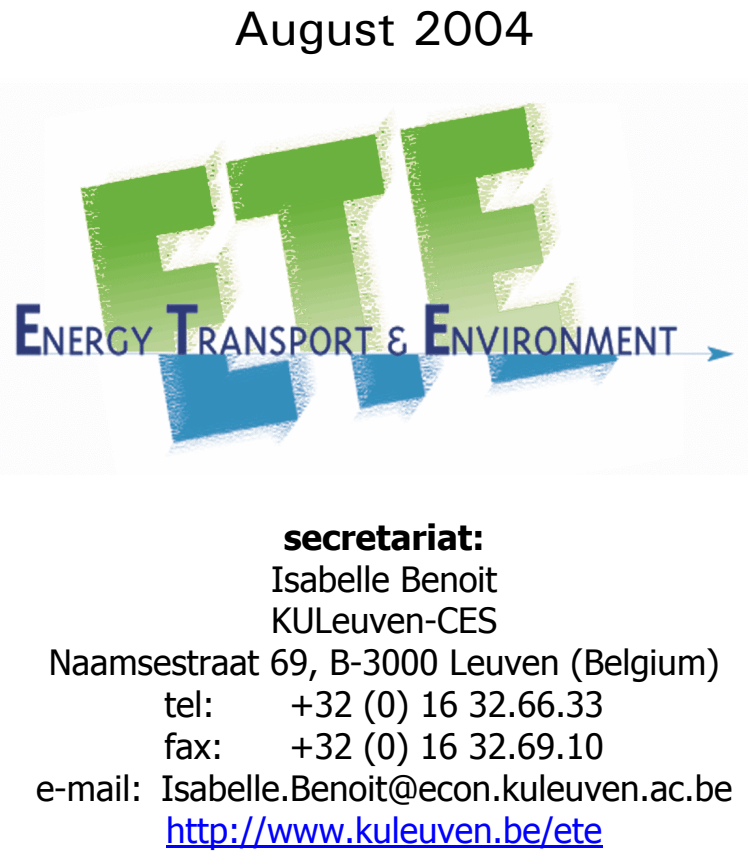




\title{
Regulating on-street parking
}

\author{
Edward Calthrop ${ }^{\mathrm{A}^{*}}$ and Stef Proost ${ }^{\mathrm{B}}$ \\ ${ }^{\mathrm{A}}$ CER, Brussels, Belgium. \\ ${ }^{\mathrm{B}}$ Catholic University of Leuven, Belgium.
}

\begin{abstract}
Consider a shopper or tourist driving downtown and trying to park. Two strategies are usually available: either park at a private off-street facility or search for a cheaper on-street spot. We formalise such a setting and use the model to study optimal government regulation of the on-street parking market. It is shown that the optimal on-street fee equals the marginal cost of off-street supply at the optimal quantity. If the off-street market is supplied under constant returns to scale, this provides a particular simple operational rule: the price on street should match that off street. We also extend the model to consider maximum length of stay restrictions and non-competitive private supply. A numerical model, calibrated to central London, investigates the magnitude of an optimal fee.
\end{abstract}

Keywords: Parking, Regulating urban transport, Search.

JEL Classification: R40 (Transport systems - general); R48 (Transport systems government pricing); L92 (Industry studies: transportation); H42 (Publicly provided private goods).

- Corresponding author. This paper was mostly written during my doctoral studies at the Catholic University of Leuven, and polished during a post-doc at Jesus College, Oxford. Address: Community of European Railways (CER), Avenue des Arts 53, B1000, Brussels. Tel.:+32(0)2 21308 39; Fax: +. E-mail address: edward.calthrop@,cer.be

- this paper is a revised version of paper 2002-02 


\section{Introduction}

In most cities of the industrialised world, governments intervene in the urban parking market on a regular basis. Common examples include the setting (and enforcing) of on-street parking fees and maximum length of stay restrictions, the direct provision of space on street and the use of the planning system to regulate private supply. When considering the microeconomics of this intervention, a natural focal point to consider is the first-best price of a fixed supply of space on street. ${ }^{1}$

Three recent papers (Verhoef, Nijkamp and Rietveld (1995), Arnott and Rowse (1999) and Anderson and de Palma (2003)) consider the first-best pricing of on-street parking space. However all these articles, as well as the non-formal seminal piece in this area by William Vickrey (1959), consider the problem in the absence of the off-street (or facility) parking market.

This seems overly restrictive. Consider a shopper or a tourist driving downtown and deciding where to park. Two strategies are commonly available: either proceed to an off-street (and often private) parking facility or search for a vacant spot on street. If parking on street is cheaper than off street, a driver who successfully finds a vacant on-street spot enjoys greater surplus than an off-street parker. In equilibrium, therefore, a subset of drivers will choose to search such that the average search cost equals the expected value of the additional surplus. The lower the relative price of onstreet parking (relative to the off-street market), the greater the number of drivers that 'invest' in socially wasteful searching. In order to minimise search costs, therefore, the government can set the on-street meter fee equal to the off street price. Indeed, if the

\footnotetext{
${ }^{1}$ Several authors also consider the optimal price of parking in the presence of underpriced externalities associated with road use e.g. Arnott et al. (1991), Glazer and Niskanen (1992) and Calthrop et al. (2000). See also Young (2000) for a review of engineering models of parking.
} 
supply of off-street space is competitive, we will show that this rule is welfare maximising.

This insight also has implications in terms of the choice of on-street regulatory instrument adopted by the government. The additional surplus from parking on street is relatively large if parking is free (albeit subject to a maximum length of stay restriction). We might therefore expect more searching when the on-street market is regulated via a time restriction than a meter fee. In short, effective management of the on-street market would seem to depend in an important way upon pricing conditions at the rival facility market. This element is missing from the existing literature on parking.

We construct a simple model to analyse optimal on-street parking regulation in the presence of a close substitute market. If the private off-street market is competitive, we derive a simple welfare maximising policy rule: set the price per time unit on street equal to the resource cost of off-street parking at the optimal quantity. In the case of constant returns to scale, this rule is particularly easy to implement. Optimal on-street regulation reduces to matching the price off street. Pricing below this rate induces too many drivers to invest in socially wasteful searching. Pricing higher induces all drivers to use the off-street market, which results in excessive supply costs (compared with drivers using the zero-resource cost on-street space).

Our findings differ from the existing literature. Vickrey (1959) assumes an aggregate demand curve for on-street parking defined over own-price alone and advocates a policy of peak-load pricing. ${ }^{2}$ But this formulation is somewhat unsatisfactory: for instance, how does the peak-load price relate to the price charged

\footnotetext{
${ }^{2}$ Vickrey (1959) also considers uncertain demand. He advocates a 'demand-responsive' pricing rule: allow the meter fee rate to rise with the occupation rate in the immediate vicinity. As Arnott and Rowse (1999) note, however, this is not guaranteed to result in a first-best allocation.
} 
on the rival market? Our reasoning above suggests that aggregate search needs to be specified as a function of the price on both parking markets.

Both Arnott and Rowse (1999) and Anderson and de Palma (2003) ${ }^{3}$ consider on-street pricing in explicitly spatial settings. On-street parking is an open-access resource: drivers' decisions are based on the average rather than the marginal search cost. The optimal parking fee is shown to equal the marginal external search cost, which aligns private incentives with the social planner's. Both papers assume that (on-street) parking spots are imperfect substitutes. Arnott and Rowse (1999) assume a homogeneous city located on the outside of a circle. Symmetry implies that the optimal parking fee is independent of location. Anderson and de Palma (2003) assume a linear city in which spots nearer the single point $\mathrm{CBD}$ are more desirable than those further away (due to reduced walk time). In equilibrium, the density of parking declines with distance from the CBD. As a result, marginal external search cost, and hence the optimal fee, declines with distance from the CBD.

These findings are important and relate primarily to the explicitly spatial nature of the search process. However, as stressed above, they abstract from the presence of a rival off-street market. In order to focus sharply on the influence of a rival market, we adopt a highly reduced form representation of space. We also abstract from randomness in demand. In this regard, our model differs from the wellknown findings on endogenous search processes (e.g. De Vany (1976), De Vany and Savings (1977)).

We extend our basic model in two directions, both new to the literature.

Firstly, we examine both quantity and price regulation. In many urban areas, on-street time restrictions, permitting a maximum length of stay, are a common alternative to

\footnotetext{
${ }^{3}$ This paper can be seen as a generalisation of Verhoef et al. (1995)
} 
meter fees. We show that a simple time restriction, in which the driver pays no charge as long as he parks for less than a given length of time, is welfare inferior to an optimal meter fee. Secondly, we consider the optimal on-street pricing policy in the realistic setting of a non-competitive off-street market. We adopt a simple Stackelberg setting, in which the government (the leader) plays against a single off-street supplier (the follower). We show that the optimal price on street deviates from the matching rule. Rather, a 'knife-edge' result emerges. The on-street price is either raised just to the point that the off-street supplier is induced to undercut the on-street market, or it is raised as high as possible without inducing undercutting. In our numerical model, calibrated to central London, we show, perhaps surprisingly, how often it is optimal for the on-street market to be undercut. In doing so, government loses tax revenues, but this is more than outweighed by the gain in consumer surplus from lower parking prices. However, the reverse case is also well within the range of plausible parameters.

The structure of the paper is as follows. In section 2 we set out the basic model. Section 3 examines the centralised allocation problem: how would demand be allocated to supply if government can control all driver decisions? This is an important benchmark. Section 4 compares the optimal centralised allocation with that attainable under decentralised decision making when the off-street market is supplied by a perfectly competitive market. Both linear and non-linear pricing schedules are considered. Section 5 relaxes the competitive off-street market assumption. Results are derived analytically and optimal values are computed with a numerical example. Sensitivity analysis investigates the generality of findings. Section 6 concludes.

We conjecture that the findings in this paper (in the context of parking policies) may be relevant to the general theory on the public provision of private 
goods. The essence of the model is that the public sector has a cost advantage over private supply, at least for an initial number of units. Rationing is random. This structure suggests a relevance to the health sector (with rationing by waiting times) or utility provision (with rationing by shortage). The paper's findings also relate to the literature on public policy in a duopoly market (see Bös (1985)).

\section{The model}

\subsection{Consumer benefit}

We assume a continuum of $N$ identical risk-neutral consumers. To simplify matters, we assume that the utility from parking for $t$ units of time (during the peak period) is given by a quasi-linear function, $u(t)$. This function is assumed to be continuous and strictly concave $\left(u^{\prime \prime}(t)<0\right)$, while the marginal benefit of parking is assumed to be exhausted after time $T$ (thus $u^{\prime}(T)=0$ ). Parking is supplied on two markets: an on-street market (indexed by $X$ ) and off-street market (indexed by $Y$ ). The two markets are perfect substitutes. ${ }^{4}$

On either market, a consumer decides how long to park on the basis of a constant per time unit fee, $p_{i}$ with $i \in\{X, Y\}$ (In section 4.2. we explore the use of non-linear pricing schedules). Each consumer parks until the marginal benefit equals marginal cost: $u^{\prime}\left(t_{i}\right)=p_{i}$ and hence $t_{i}\left(p_{i}\right)$. Consumer surplus, conditional on using market $i$, is denoted by $v\left(p_{i}\right)$. Finally, note that concavity of the utility function implies a shorter length of stay if the price rises i.e. $t_{i}^{\prime}=1 / u^{\prime \prime}\left(t_{i}\right)<0$.

\footnotetext{
${ }^{4}$ This assumption can be easily relaxed: one market might be safer than another, or closer to a desired destination. In a model with identical consumers, however, this difference just acts as a fixed term. We comment further on preference heterogeneity in the concluding section.
} 


\subsection{Supply technology}

The on-street market is characterised by a fixed supply of space, such that aggregate demand equals on-street supply when each individual parks for $Q$ units of time ( $Q>0)$. The opportunity cost of on-street parking space is assumed to be zero. In contrast, aggregate parking time, $N t$, is supplied off-street with a continuous, increasing and convex cost function, $C(N t)$. To keep the problem interesting, we assume $u^{\prime}(0)>C^{\prime}(0)$. We consider both the case of constant returns to scale $\left(C^{\prime \prime}=0\right)$ and a fixed capacity constraint at $N r$ units of time, $\left(C^{\prime}(N r)=\infty\right)$.

\subsection{Rationing rule}

If demand for on-street parking is greater than supply, we assume that the probability of finding a vacant on-street spot is given by a random-rationing rule, familiar from the literature on capacity-constrained firms (see, for example, Davison and Deneckere (1986)). Denoting the fraction of consumers that choose to search for a vacant on-street spot by $\lambda$, the per capita demand for on-street parking is $\lambda t_{X}$. Thus the probability of finding a vacant on-street spot, $\rho$, is given by

$$
\rho\left(p_{X}, \lambda\right)=\operatorname{Min}\left\{\frac{Q}{\lambda t_{X}\left(p_{X}\right)}, 1\right\} .
$$

For any given price for on-street parking, the probability of finding a vacant spot, $\rho$, equals 1 if the fraction of consumers choosing to search, $\lambda$, is less than or equal to $Q / t_{X}$. To ease notation below, we denote the number of searchers, such that demand at a particular price equals supply as $\bar{\lambda}\left(p_{X}\right)$. 
The rationing rule is justified if drivers arrive in a downtown area more or less at random. We consider this well suited to modelling parking in city centres for shopping, tourism and leisure activities. It is clearly far less suited to modelling workplace parking, where spots are often reserved.

\subsection{Search costs}

Searching for an on-street spot is assumed costly. This cost is denoted by $S$. An explicit expression for $S$ might be derived from first principles using stochastic queueing theory, depending upon assumptions regarding consumer behaviour (length of stay, decision to balk or not) and supply conditions (number of servers, servers in parallel or series etc.). In general, however, closed form solutions do not exist (see, for example, Grimmet and Stirzaker (2001)). We therefore adopt a reduced-form representation consistent with a central feature of formal queueing models: the shorter the average length of stay (i.e. the greater the expected service rate), the lower the expected search cost. ${ }^{5}$ Thus we specify a continuous function $S(\rho)$ with $S^{\prime}<0$. Moreover, we assume that the expected search cost equals zero if a vacant spot is found for certain: $S(1)=0$.

\subsection{Equilibrium number of searchers}

\footnotetext{
${ }^{5}$ For instance, the explicit wait time for a simple M/D/1 queue is given by $\lambda / 2(1-\sigma) \mu^{2}$ where $\lambda$ is the expected arrival rate (and equivalent to $\lambda$ in our model), $\mu$ is the service rate (equivalent to the inverse of $t_{X}$ in our model) and $\sigma \equiv \lambda / \mu$. It is clear that wait time declines in the service rate.
} 
Each consumer decides whether to search for an on-street spot or proceed directly to the off-street market. The expected payoff from searching for a vacant onstreet spot is given by

$$
v_{S}\left(p_{X}, p_{Y}, \lambda\right)=\rho v\left(p_{X}\right)+[1-\rho] v\left(p_{Y}\right)-S(\rho)
$$

where, recall, $\rho$ is a function of $\lambda$ and $p_{X}$. This equation can be solved for the equilibrium number of searchers, $\lambda^{*}$ i.e. a number of searchers such that any one consumer cannot increase her expected payoff by switching from searching to not searching, or vice-versa. For a non-symmetric equilibrium, i.e. $0<\lambda<1$, this implies that $\lambda^{*}$ is such that

$$
v_{S}\left(p_{X}, p_{Y}, \lambda^{*}\right)=v_{Y}\left(p_{Y}\right)
$$

Substituting from (2) into (3), with simple re-arrangement, gives that in equilibrium, consumers search until the expected net surplus from searching equals the expected marginal cost, or

$$
\rho\left[v\left(p_{X}\right)-v\left(p_{Y}\right)\right]=S(\rho) .
$$

Recall $\rho=\rho\left(p_{X}, \lambda\right)$. Hence equation (4) can be solved to give $\lambda^{*}\left(p_{X}, p_{Y}\right)$ when $p_{X} \leq p_{Y} \cdot{ }^{6}$ If not, i.e. $p_{X}>p_{Y}$, all drivers park off street and $\lambda^{*}=0$. To simplify the analysis, we restrict attention to $\lambda^{*}<1 .^{7}$ If $p_{X}=p_{Y}$, condition (4) holds if and only if $\rho=1$. This is the case, recalling (1), if $\lambda^{*} \in\left[0, \bar{\lambda}\left(p_{Y}\right)\right]$. To ensure existence of optima, we assume $\lambda^{*}\left(p_{Y}, p_{Y}\right)=\bar{\lambda}\left(p_{Y}\right)$ i.e. drivers have an epsilon preference for

\footnotetext{
${ }^{6}$ It is straightforward to show that the derivative of $v_{S}$ with respect to $\lambda$ is negative i.e. an interior solution, when it exists, is unique.

${ }^{7}$ Although conceptually straightforward to include, allowing for $\lambda^{*}=1$ complicates the notation without adding addition insight - see Calthrop and Proost (2002). Moreover, this assumption is consistent with our numerical model (Figure 1).
} 
parking on street. This implies that the $\lambda^{*}$ function is discontinuous: as $p_{X} \rightarrow p_{Y}$ from above, $\lambda^{*}$ jumps (in the limit) from 0 to $\bar{\lambda}$.

\section{INSERT FIGURE 1 AROUND HERE}

Figure 1 plots the equilibrium number of searchers from our numerical model. We assume a linear demand curve for parking and constant returns to scale off-street. The unknowns in our model are calibrated to data published for central London. The details of this procedure are provided in Annex B. The Figure plots three functions. The dashed line plots $\bar{\lambda}\left(p_{X}\right)$ : the fraction of drivers such that $\rho=1$. For example, with a price of $€ 10$ per hour, approximately one-third of all drivers can be accommodated on street. At the higher price of $€ 25$ per hour, each driver parks for a shorter period of time, and thus nearly one-half of all drivers can park on street. The set to the northwest of this function contains $\left(p_{X}, \lambda\right)$ combinations such that $\rho=1$. Conversely, the open set to the southeast of this function contain $\left(p_{X}, \lambda\right)$ combinations such that $\rho<1$.

The 'thick' functions plot $\lambda^{*}$ as a (discontinuous) function of $p_{X}$ with the offstreet price set at either $€ 7$ or $€ 23.5$. (These prices equal the marginal resource cost of off-street parking and the monopoly price, respectively). Consider first the lower function, $\lambda^{*}\left(p_{X}, 7\right)$. If $p_{X}>7$, all drivers park off street and $\lambda^{*}=0$. If, on the other hand, $p_{X}<7$, the net surplus from parking on street induces some drivers to search and $\lambda^{*}>0$. The discontinuity in the function appears when $p_{X}=7$ i.e. prices are equal across the two markets. 
The sign of $\partial \lambda^{*} / \partial p_{X}$ is, in general, ambiguous (in the region $p_{X}<p_{Y}$ ). Holding $\rho$ constant, it is clear from equation (4) that increasing $p_{X}$ reduces the net surplus from parking on street, $v\left(p_{X}\right)-v\left(p_{Y}\right)$, and $\lambda^{*}$ falls. However, increasing $p_{X}$ also reduces driver length of stay and thus increases the probability of finding a vacant spot, $\rho$. Increasing $\rho$, ceteris paribus, increases the expected value of the net surplus from searching and reduces expected search cost. Hence $\lambda^{*}$ increases. In general, either effect may dominate. ${ }^{8}$ In Figure $1, \lambda^{*}\left(p_{X}, 7\right)$ falls in own price: the reduction in net surplus dominates. This is not the case for $\lambda^{*}\left(p_{X}, 23.5\right)$, which increases in own price at values of $p_{X}$ below approximately 20 . In this region, the increased probability of finding a spot and reduced search costs dominate. By contrast, the sign of $\partial \lambda^{*} / \partial p_{Y}$ is unambiguously positive (in the region $p_{X}<p_{Y}$ ). Increasing the off-street price increases the gain from parking on street and $\lambda^{*}$ increases.

\subsection{Equilibrium demand for off-street parking}

Demand for off-street parking per consumer, $D_{Y}$, is given by a fraction of consumers, $1-\lambda$, who proceed directly to the market, plus the fraction who search, $\lambda$, but fail to realise a vacant spot, $1-\rho$. Thus

$$
\begin{aligned}
D_{Y}\left(p_{X}, p_{Y}\right) & =t_{Y}\left[\left(1-\lambda^{*}\right)+(1-\rho) \lambda^{*}\right] \\
& =t_{Y}\left[1-\rho \lambda^{*}\right] .
\end{aligned}
$$

\footnotetext{
${ }^{8}$ Standard manipulations reveal that $\partial \lambda^{*} / \partial p_{X}<0$ if $t_{X} p_{X}>\left[v\left(p_{X}\right)-v\left(p_{Y}\right)-S^{\prime}\right]|\varepsilon|$, where $\varepsilon$ is the elasticity of parking time (with respect to own price). A lower absolute value of the elasticity and $S^{\prime}$
} 
Consider different parameter regions. If $p_{X}>p_{Y}$, all drivers park off street i.e. $\lambda^{*}=0$ and $D_{Y}=t_{Y}\left(p_{Y}\right)$. If $p_{X} \leq p_{Y}$, the off-street market receives only residual parking demand i.e. $D_{Y}=t_{Y}\left(p_{Y}\right)\left[1-\bar{\lambda}\left(p_{X}\right)\right]$.

\subsection{Social welfare}

Expected social welfare is given by an unweighted sum of expected consumer surplus (from searching or not), expected on-street parking tax revenue and off-street producer surplus. This latter term can be written as $N D_{Y} p_{Y}-C\left(N D_{Y}\right)$. Social welfare, $W$, is therefore given by

$$
\begin{aligned}
W\left(p_{X}, p_{Y}\right)= & N\left[\lambda^{*} v_{S}+\left(1-\lambda^{*}\right) v\left(p_{Y}\right)\right]+ \\
& N\left[\lambda^{*} \rho t_{X} p_{X}\right]+ \\
& N D_{Y} p_{Y}-C\left(N D_{Y}\right) .
\end{aligned}
$$

In sections 4 and 5 below, the government is assumed to maximise this function with respect to the on-street price of parking, for different assumptions as to price formation on the off-street market. Before turning to these cases, however, it is revealing to examine the optimal centralised allocation.

\section{Centralised allocation}

Social welfare is given by expression (6). In this section we derive the optimal centralised solution i.e. we maximise social welfare with respect to three control variables: the fraction of drivers parking on street $(\lambda)$, and the length of stay both on and off street $\left(t_{X}, t_{Y}\right)$. It is straightforward to restrict the potential solution space to 
this problem: it can never be optimal to have positive search costs (and thus

$\left.\lambda t_{X} \leq Q\right)$; the inherent cost advantage of the on-street market implies that some

consumers must always be allocated to it; declining marginal utility implies that all consumers must consume on one or other of the available markets. Using these, plus other simplifications (see Annex A), we write the optimisation problem confronting the government as one of maximising welfare, $W$

$$
W\left(\lambda, t_{X}, t_{Y}\right)=N\left[\lambda u\left(t_{X}\right)+[1-\lambda] u\left(t_{Y}\right)\right]-C\left(N[1-\lambda] t_{Y}\right),
$$

subject to two inequality constraints

$$
\begin{aligned}
& h_{1}\left(\lambda, t_{X}\right)=1-\lambda \geq 0 \\
& h_{2}\left(\lambda, t_{X}\right)=Q-\lambda t_{X} \geq 0 .
\end{aligned}
$$

As shown in Annex A, the optimal solution ${ }^{9}$ to this problem depends on two parameters: $Q$ and $C^{\prime}(0)$ plus the utility function. This is shown in Figure 2, assuming, for simplicity, that $N=1$. Aggregate parking supply is shown as a thick function. $Q$ units (on street) are provided at zero resource cost. Thereafter, (off-street) parking is provided at a positive marginal cost.

\section{INSERT FIGURE 2 AROUND HERE}

Consider the case $Q>T$ (recall $T$ is the length of stay at which the marginal benefit of parking is zero). This case is given in the Figure by demand curve $u_{1}^{\prime}$. Onstreet supply is sufficiently large that, even when each consumer parks until marginal benefits are exhausted, demand is less than supply. In the optimal allocation, all

reduction in net surplus effect dominates.

${ }^{9}$ As is well known, if a global maximum exists to this problem, and if constraint qualification is met at that point, then the optimal solution is a critical point to the Kuhn-Tucker problem (see, for example, 
consumers park on street and thus save off-street supply costs. Now, consider demand curve $u_{2}^{\prime}$. In this case $Q<T$. As $u_{2}^{\prime}(Q)<C^{\prime}(0)$, it is optimal to allocate all parking demand to the on-street market, although it is necessary to restrict parking time to $t_{X}=Q$ so that demand equals supply. Finally, consider the case $u_{3}^{\prime}$. In this case $u_{3}^{\prime}(Q)>C^{\prime}(0)$. Annex A confirms that, as expected, the optimal allocation involves using both parking markets.

We assume henceforth that $u^{\prime}(Q)>C^{\prime}(0)$ (as in case 3 in the Figure). This is the relevant case for large metropolitan areas, where off-street parking forms a significant share of the overall parking market. This contrasts with the existing parking literature which, by abstracting from the off-street market, implicitly assumes (in terms of our model) that $0<u^{\prime}(Q) \leq C^{\prime}(0)$. This assumption, as argued in the introduction, seems unduly restrictive.

Annex A presents the formal proof of the optimal centralised allocation. However, the solution is quite intuitive. Firstly, for any given level of parking demand, total surplus is maximised when marginal utilities are equal across markets, which implies that drivers park for an equal length of time on either market or $t_{X}^{* *}=t_{Y}^{* *}$ (where the double star superscript denotes the optimal centralised allocation).

Secondly, the on-street market is fully utilised i.e. $\lambda^{* *}=Q / t_{X}^{* *}=\bar{\lambda}\left(t_{X}^{* *}\right)$. Finally, it is necessary to have an efficient quantity of total parking, which is met when $t_{Y}^{* *}$ (or equally $t_{X}^{* *}$ ), is set such that marginal benefit equals marginal cost, or $u^{\prime}\left(t_{Y}^{* *}\right)=C^{\prime}\left(N\left[t_{X}^{* *}-Q\right]\right)$. This is shown on Figure 2. 
For ease of comparison with later results, we collect the central result from the optimal allocation problem in the form of a Lemma:

Lemma 1 Assuming $u^{\prime}(Q)>C^{\prime}(0)$, the optimal central allocation $\left(\lambda^{* *}, t_{X}^{* *}\right.$ and $\left.t_{Y}^{* *}\right)$ is given by

$$
\begin{aligned}
& t_{X}^{* *}=t_{Y}^{* *} \\
& u^{\prime}\left(t_{X}^{* *}\right)=C^{\prime}\left(N\left[t_{X}^{* *}-Q\right]\right) \\
& \lambda^{* *}=\bar{\lambda}\left(t_{X}^{* *}\right)
\end{aligned}
$$

Proof: See Annex Al

In order to derive explicit results, we examine a special case.

Example Assume that the quasi-linear utility function is quadratic (in parking time), such that $u^{\prime}(t)=1-t$ and hence $T=1$. Furthermore, assume that off-street parking is supplied under constant returns to scale, and thus $C^{\prime}(t)=C^{\prime}$, a constant. Under the assumptions of Lemma 1 , namely that $Q<1-C^{\prime}$, the optimal centralised allocation is given by

$$
\begin{aligned}
& t_{X}^{* *}=t_{Y}^{* *}=1-C^{\prime} \\
& \lambda^{* *}=\frac{Q}{1-C^{\prime}} .
\end{aligned}
$$

\section{Perfect competition off-street}

Can the optimal central allocation be decentralised? This is not obvious. In our centralised allocation problem the government uses three control variables. In a realistic market economy, however, we assume that the government has one: the price 
of on-street parking. In particular, it can only indirectly control the number of searchers via equation (4).

We examine this problem under the assumption that off-street suppliers take price as fixed. This assumption may be unrealistic in some cities, but it establishes an interesting benchmark case - section 5 below examines a non-competitive case. In section 4.1., we show that the government can decentralise the first best allocation using a linear fee. In section 4.2., we consider non-linear fee schedules.

\subsection{Linear on-street price}

The optimal on-street price can be derived by maximising social welfare, given by equation (6). However, we proceed more directly by demonstrating that a particular on-street fee results in the optimal centralised allocation in Lemma 1. Our candidate solution is a price, $p_{X}^{*}$, such that $t_{X}\left(p_{X}^{*}\right)=t_{X}^{* *}$. Assume, for a moment, that the off-street price is identical to the on-street price, i.e. $p_{X}^{*}=p_{Y}^{*}$. If so, off-street demand is $N\left[t_{X}^{* *}-Q\right]$, and given perfect competition

$$
u^{\prime}\left(t_{Y}\left(p_{Y}^{*}\right)\right)=C^{\prime}\left(N\left[t_{X}^{* *}-Q\right]\right) .
$$

By definition of $t_{X}^{* *}$, this implies that $t_{Y}\left(p_{Y}^{*}\right)=t_{X}\left(p_{X}^{*}\right)=t_{X}^{* *}$ and hence prices are identical across markets. This being the case, it is also clear that the equilibrium number of searchers equals $\bar{\lambda}\left(t_{X}^{* *}\right)$. All three conditions of Lemma 1 are met. The resulting allocation is therefore first best. We summarise this result in a Proposition.

Proposition 1: Given a perfectly competitive off-street parking market, a sufficient condition to maximise social welfare is to set the constant per time unit price of on- 
street parking equal to the marginal cost of off-street supply at the optimal level of off-street demand. The resulting allocation is first best.

Proof: In text

In order to solve this problem, government needs to know consumer utility functions and the off-street supply function (though no information is required on the shape of the search cost function). However, a particularly simple policy emerges if the off-street market is supplied under constant returns to scale. To set the optimal onstreet price, government just matches the price of off-street parking.

Corollary 1: If the off-street market is supplied under constant returns to scale and perfect competition, the optimal on-street price matches the price off-street i.e. $p_{X}^{*}=C^{\prime}=p_{Y}^{*}$.

Corollary 1 is also directly seen from Figure 1 . If the marginal cost of offstreet parking is $€ 7$ per hour, and the on-street price is set to match this price, it is clear that $\lambda^{*}=\bar{\lambda}=\lambda^{* *}$. Consider other pricing options. A higher on-street price results in all consumers using the off-street market and the total costs of parking supply are too great. A lower price is also sub-optimal as total search costs are excessive.

\subsection{Non-linear on-street price schedule}

Non-linear pricing schedules, including the limiting case of a time restriction, are commonly applied to on-street parking markets. Proposition 1 establishes that a 
linear fee is sufficient to implement the optimal centralised allocation. But it is not necessary: a non-linear fee can give the same outcome.

Recall that the optimal fee structure decentralises the conditions of Lemma 1. Each consumer parks for $t_{X}^{* *}$ units of time, and a fraction $\lambda^{* *}=\bar{\lambda}$ of consumers search. An infinite number of fee structures meet these conditions. Denote the total on-street fee as $F_{X}(t)$. Consider a one-part fee structure given by

$$
F_{X}(t)=\left\{\begin{array}{cc}
p_{X}^{*} t_{X}^{* *} & \text { if } t \leq t_{X}^{* *} \\
\infty & \text { otherwise }
\end{array}\right.
$$

If a consumer parks on street, he parks for $t_{X}^{* *}$ units of time and gains surplus $v\left(p_{X}^{*}\right)$.

Hence, from equation (4), if $p_{Y}=p_{X}^{*}$ then $\lambda=\lambda^{* *}$. The residual demand for off-street parking is provided at marginal cost equal to $p_{Y}^{*}$. All three conditions of Lemma 1 are met. The resulting allocation is first best.

It is common to observe a particular form of time restriction, which we term a 'simple time restriction', in which drivers park for free up to a certain limit, $r$, and then must depart. It has a form

$$
F_{X}(t)=\left\{\begin{array}{cc}
0 & \text { if } \mathrm{t} \leq \mathrm{r} \\
\infty & \text { otherwise }
\end{array}\right.
$$

A simple time restriction ${ }^{10}$ cannot be first best. Consider a candidate solution, $r=t_{X}^{* *}$, which, to ease notation, we re-write as an implicit price, $p_{X}^{r}$ such that $p_{X}^{r}=u^{\prime}(r)$, where, of course, $p_{X}^{r}=p_{X}^{*}=p_{Y}^{*}$. The resulting allocation is not first best. Rather, the consumer surplus from parking on street under such an instrument is equal to $v\left(p_{X}^{*}\right)+p_{X}^{*} r$, greater the $v\left(p_{X}^{*}\right)$ obtained with a linear fee. As a consequence, too

\footnotetext{
${ }^{10}$ In fact any strictly convex fee schedule in which $F_{X}(0)=0$ fails to decentralise the first best. A simple time restriction is, of course, just a limiting case of such a function.
} 
many drivers search. To see this, rewrite equation (4), which gives an implicit equation for the optimal fraction of searchers,

$$
\rho\left[v\left(p_{X}^{r}\right)+p_{X}^{r} r-v\left(p_{Y}^{*}\right)\right]=S(\rho)
$$

which simplifies to

$$
\rho p_{Y}^{*} r=S(\rho) .
$$

This expression cannot be solved by $\lambda=\bar{\lambda}$ (and thus $\rho=1$ ). Hence $\lambda>\lambda^{* *}$. The third condition of Lemma 1 is not met.

Consider an alternative candidate solution. The time restriction, $r$, can be set such that the first best fraction of consumers search, $\lambda=\lambda^{* *}$. This is done by setting the implicit price of the simple time restriction, $r$ such that $v\left(p_{X}^{r}(r)\right)+p_{X}^{r}(r) r=v\left(p_{Y}^{*}\right)$. Concavity of the utility function implies that this can only hold when $p_{X}^{r}>p_{Y}^{*}$ or $r<t_{X}^{*}$. The first condition of Lemma 1 is not met.

Calthrop and Proost (2002) derive the optimal simple time restriction (in the case of constant returns to scale in off-street supply). Not surprisingly, it falls between the two extreme cases considered above. Shortening the length of stay on street (relative to the off-street market) incurs welfare costs from an inefficient allocation, but reduces incentives to search. The optimal simple time restriction trades off these two distortions in an efficient manner.

\section{Off-street market power}

The off-street market is unlikely to be perfectly competitive. Spatial separation, at the very least, gives rise to market power. We adapt our model to investigate optimal on-street parking policy in such a setting. Firstly, we assume a 
single supplier of off-street parking space, who supplies at constant marginal cost $C^{\prime} .{ }^{11}$ Secondly, we assume a simple sequential game, in which the government acts as a Stackelberg leader. ${ }^{12}$ This seems reasonable: governments are often constrained in their ability to change prices quickly. The private off-street supplier (the follower) observes the price on street and responds by setting a profit-maximising off-street price. Finally, to simplify matters, we focus on the case in which both players use a constant per time unit fee only.

Recall from Corollary 1 that under perfect competition and constant returns to scale, the optimal policy for the government to pursue is just one of matching the offstreet price. When the off-street market is non-competitive, however, this is shown to no longer be the case.

\subsection{Analytics}

As is standard, we solve the game backwards. The off-street supplier maximises profits for given on-street price.

Stage 2: Off-street supplier sets profit-maximising price

Recall expression (5) for the equilibrium demand for off-street parking. If all consumers use the off-street market, i.e. $D_{Y}=t_{Y}\left(p_{Y}\right)$, profit is maximised at the monopoly level, such that the percentage mark-up of price over marginal cost is equal

\footnotetext{
${ }^{11}$ Allowing for convex technology is straightforward though notationally cumbersome.

${ }^{12}$ In choosing for a Stackelberg framework, we assume that the government can commit. Calthrop (2001) analyses Nash equilibria in a simultaneous move version of this game. However, the payoff functions of players are neither quasi-concave in own price nor upper semi-continuous in the joint price
} 
to the inverse of the (absolute value of the) elasticity of parking time. We denote this monopoly price $p_{Y}^{m}\left(C^{\prime}\right)$. If $p_{X}>p_{Y}^{m}$, the firm can do no better than charge $p_{Y}^{m}\left(C^{\prime}\right)$. If $p_{X} \leq p_{Y}^{m}$, the firm faces a choice of strategy: either undercut the on-street market by epsilon and capture the full demand curve, or price at $p_{Y}^{m}\left(C^{\prime}\right)$ on the residual demand curve.

The profit (per person) from undercutting (subscript $U$ ) the on-street market ${ }^{13}$ is given by

$$
\pi_{U}\left(p_{X}\right)=\left[p_{X}-C^{\prime}\right] t_{Y}\left(p_{X}\right)
$$

while the profit (per person) from playing the monopoly price (subscript M) on the residual demand curve is

$$
\pi_{M}\left(p_{X}\right)=\left[p_{Y}^{m}-C^{\prime}\right] t_{Y}\left(p_{Y}^{m}\right)\left[1-\frac{Q}{t_{X}\left(p_{X}\right)}\right] .
$$

Consider two extreme values for the on-street price. If $p_{X}=C^{\prime}$, undercutting leads to negative profit. Therefore the firm sets the monopoly price and makes positive profits on the residual demand curve. Alternatively, if $p_{X}=p_{Y}^{m}$, equations (10) and (11) show that undercutting is more profitable than setting price equal to $p_{Y}^{m}$.

Between these two extreme values, there exists an on-street price at which the off-street supplier is indifferent ${ }^{14}$ between undercutting and playing the monopoly price. We denote this indifferent price by $I\left(Q, C^{\prime}\right)$, given by the solution to the implicit equation $\pi_{U}(I)=\pi_{M}(I)$, where it follows that $C^{\prime}<I<p_{Y}^{m}$. The bestresponse function of the off-street supplier is given by

vector. Equilibria in pure-strategies need not exist (see Dasgupta and Maskin (1986)), while mixed strategy equilibria are awkward to compute.

${ }^{13}$ This is the profit in the limit as epsilon tends to zero.

${ }^{14}$ To avoid unnecessary technicalities, we again assume an epsilon preference: the firm is assumed to undercut (play aggressively) when faced with price $I$. 


$$
b_{Y}\left(p_{X}\right)=\left\{\begin{array}{ccc}
p_{Y}^{m} & \text { if } & p_{X}<I \\
p_{X} & \text { if } & I \leq p_{X} \leq p_{Y}^{m} \\
p_{Y}^{m} & \text { if } & p_{X}>p_{Y}^{m} .
\end{array}\right.
$$

The intuition behind the best response function is straightforward. Undercutting is attractive when the on-street price is relatively high (though less than the monopoly price): the loss in profit per unit, compared with the monopoly price, is more than compensated for by having the full rather than residual demand. If the on-street price is relatively low, however, the reverse is true.

The best response function is discontinuous: the off-street supplier jumps from playing the monopoly price to undercutting as the on-street price tends to $I$ from below. Comparative statics reveal that

$$
\frac{\partial I}{\partial Q}<0 \quad ; \quad \frac{\partial I}{\partial C^{\prime}}>0
$$

Increasing $Q$ reduces the residual demand curve for off-street parking. Undercutting becomes more attractive. Increasing $C^{\prime}$, on the other hand, by increasing $p_{Y}^{m}$, increases the profitability of capturing residual demand. Finally, note that $I$ is independent of the search cost.

Stage 1: Government sets welfare maximising on-street price

After observing the reaction of the firm in expression(12), government chooses a value of $p_{X}$ to maximise social welfare, given by ${ }^{15}$

$$
\frac{W\left(p_{X}\right)}{N}=\lambda^{*} v_{S}+\left(1-\lambda^{*}\right) v\left(b_{Y}\left(p_{X}\right)\right)+\lambda^{*} \rho t_{X} p_{X}+\left[b_{Y}\left(p_{X}\right)-C^{\prime}\right] D_{Y}
$$

\footnotetext{
${ }^{15}$ This equation is identical to equation (6) except we impose constant returns to scale.
} 
This function is, naturally, also discontinuous at price $I$. Hence we proceed by examining local optima on the subset of prices respectively higher-than and lowerthan $I$. Consider the higher-than region: $p_{X} \geq I$. The firm undercuts and all drivers use the off-street market $\left(\lambda^{*}=0\right)$. Expression (14) reduces to consumer surplus and firm profit. Welfare is thus locally decreasing in on-street price. Reducing the price on street induces the firm to reduce the price off street. Given that the price off street is above marginal cost, this increases welfare. The locally optimal on-street price is a corner solution: $p_{X}=I$. At this point, welfare (in the high region), $W^{H}$, is given by

$$
\frac{W^{H}}{N}=v(I)+\pi_{U}(I)
$$

Consider now the low price region: $p_{X}<I$. Social welfare, given in equation (14), simplifies to

$$
\frac{W\left(p_{X}\right)}{N}=\lambda^{*} v_{S}+\left(1-\lambda^{*}\right) v\left(p_{Y}^{m}\right)+Q p_{X}+\pi_{M}\left(p_{X}\right)
$$

Recall from equation (2) that, in equilibrium, $v_{S}=v\left(p_{Y}^{m}\right)$. The number of searchers adjusts such that the payoff is equal across the markets. Hence, social welfare is

$$
\frac{W\left(p_{X}\right)}{N}=v\left(p_{Y}^{m}\right)+Q p_{X}+\pi_{M}\left(p_{X}\right)
$$

All consumers gain the off-street surplus regardless of whether they search or not. Increasing the price of on-street parking has no effect on the consumer surplus of onstreet parkers: rather any reduction in welfare is exactly offset by an equal fall in search costs. There are only two effects from increasing the on-street fee: firstly, onstreet parking revenue increases and secondly, as more people are able to park onstreet, residual demand, and hence firm profit, falls. Strikingly, the change in welfare (in this local region) is equivalent to the change in joint profit. 
Taking the derivative of (17), the impact on welfare of increasing the on-street price is

$$
Q\left[1-\frac{p_{Y}^{m} t_{Y}}{p_{X} t_{X}} \frac{\varepsilon\left(p_{X}\right)}{\varepsilon\left(p_{Y}^{m}\right)}\right]
$$

where $\varepsilon$ just gives the elasticity of parking time with respect to price. Concavity implies that expression (18) is positive in the region $p_{X}<I<p_{Y}^{m}$. Welfare increases in the price on street. A higher price ensures that more consumers successfully find a vacant on-street market. This does not affect consumer surplus (as, in equilibrium, drivers make $v\left(p_{Y}^{m}\right)$ regardless of where they park). However, off-street profits and on-street tax revenues are affected. A higher price results in $Q$ units of on-street tax revenue. This gain is traded off against the reduction in firm profit. The first effect dominates, however, at an on-street price below $I$ (which recall is less than $p_{Y}^{m}$ ).

The locally optimal level of welfare ${ }^{16}$ is given by

$$
\frac{W^{L}}{N}=v\left(p_{Y}^{m}\right)+Q(I)+\pi_{M}(I)
$$

Government has a 'knife-edge' problem: in raising the on-street price to $I$ from below, welfare jumps from the level given by equation(19) to that of equation(15). We denote the difference in welfare by $\Delta W$, which is given by

$$
\begin{aligned}
\Delta W & =\left(v(I)+\pi_{U}(I)\right)-\left(v\left(p_{Y}^{m}\right)+Q I+\pi_{M}(I)\right) \\
& =v(I)-v\left(p_{Y}^{m}\right)-Q I,
\end{aligned}
$$

where the second line follows from our definition of $I$. In raising the price to $I$, the off-street supplier is induced to undercut the on-street market. All drivers use the offstreet market, gaining consumer surplus $v(I)$ rather than $v\left(p_{Y}^{m}\right)$. However, as all drivers switch to parking off-street, the government loses $Q I$ units of tax revenue. It 
might appear that we also need to account for a change in firm profit, though recall profits are unchanged by switching strategy at price $I$.

When is $\Delta W$ positive? Denote the derivative of $\Delta W$ with respect to $Q$ by $\Delta W_{Q}$ and note

$$
\Delta W_{Q}=-\left[I+Q \frac{\partial I}{\partial Q}\right]+v^{\prime} \frac{\partial I}{\partial Q}
$$

where, as established above, $\partial I / \partial Q<0$. The first term in brackets captures the net loss in revenue from greater on-street supply. The second term captures the increase in consumer surplus from reducing $I$. The overall sign is ambiguous.

Secondly, denoting the corresponding derivative with respect to the marginal cost of off-street supply by $\Delta W_{C^{\prime}}$, we note

$$
\Delta W_{C^{\prime}}=-v^{\prime} \frac{\partial p_{Y}^{m}}{\partial C^{\prime}}-\left(Q-v^{\prime}\right) \frac{\partial I}{\partial C^{\prime}}
$$

A higher marginal cost increases the profit-maximising price (under mild regularity conditions). This increases the net benefit from allowing the on-street market to be undercut. Higher costs also raise $I$, however, and reduce both the consumer surplus and tax revenue from being undercut.

Given the ambiguity of these terms, we use our numerical model to determine the sign of $\Delta W$.

\subsection{Numerical results}

As discussed above, our numerical model assumes linear demand curves and constant returns to scale in the supply of off-street space. Moreover, it is calibrated to

\footnotetext{
${ }^{16}$ Strictly speaking, this result holds at a price epsilon below $I$.
} 
data on central London (see Annex B). The model results are presented in Table 1. Where appropriate, results are presented in terms of $€$ per hour. For instance, under benchmark parameter values, the off-street monopoly price is $€ 23.5$ per hour, while the on-street price $I$ is $€ 14.3$ per hour.

\section{INSERT TABLE 1 AROUND HERE}

The first striking result is that $\Delta W$ is positive. This implies that the government should raise the price of parking on street until the point that the off-street monopolist undercuts the market i.e. to $€ 14.30$ but no further. Consumer surplus equals $€ 41.3$ per person. Total welfare $(W)$ is approximately 85 per cent of first best $\left(W_{F B}\right)$, which is achieved by setting the price on both markets equal to marginal cost (recall Corollary 1). If the government lowers the price by epsilon below $I$, welfare equals $W-\Delta W$, which accords to a welfare level some 70 per cent of the first best.

\subsection{Sensitivity tests}

Due to the large degree of uncertainty over parameter values, it is important to check the robustness of results. Table 2 presents our findings when varying the two key parameters: the on-street supply, $Q$, and the marginal cost of off-street supply, $C^{\prime}$. More precisely, while the first column of results reproduces the benchmark results (BMK), the second and third columns treble and halve $Q$ respectively (HI_Q and LO_Q), and the final two columns double and halve $C^{\prime}$ respectively (HI_C' and LO_C'). Model results under the relatively high parameter value are shaded. 


\section{INSERT TABLE 2 AROUND HERE}

The desirability of allowing the on-street market to be undercut seems a relatively robust result. Examining the row $\Delta W$, we see that in 4 out of 5 scenarios it is welfare improving. The only exception is with a high marginal cost of off-street supply. In this case, $I$ becomes relatively large, and the loss in tax revenues, 19.6, is sufficiently large to outweigh the (modest) gain in consumer surplus in switching from the monopoly price to $I$ (approximately 16). Given the paucity of data on this parameter, and indeed even the conceptual difficulties in identifying the shadow cost of urban land, this scenario is arguably well within the range of plausible values.

It is perhaps surprising that undercutting is socially desirable even with large variations in on-street supply, $Q$. Recall that, to ensure use of the off-street market, we assume that $u^{\prime}(Q)>C^{\prime}(0)$. In our parameterised model, this implies that $Q<4.125$. In our benchmark model, $Q=1$, though we also investigate a high case, $Q=3$, and a low case, $Q=0.5$. Raising the level of $Q$ reduces the size of residual demand and hence increases the relative profitability of undercutting. $I$ falls from 14 to 9 , which in turn increases the consumer surplus from being undercut $(60-17=43$ rather than 41-17=24). However, increasing $Q$ also increases the loss in on-street tax revenue from being undercut (27 rather than 14). The gain in consumer surplus from being undercut, however, more than outweighs the loss in tax revenue ( $\Delta W>0$ ). With a low $Q$, on the other hand, $I$ increases and both the gain in consumer surplus from being undercut and the loss in tax revenue decrease. Overall, however, it remains welfare improving to be undercut.

\section{Concluding remarks}


This paper examines the optimal regulation of the on-street parking market in the presence of a private off-street market. If the supply of on-street space relative to demand is sufficiently small, and if the supply of off-street space is competitive, the optimal price on street equals the marginal cost of off-street parking at the optimal quantity. This allocation is, moreover, first best (Proposition 1). In the case of constant returns to scale provision of space off street, this gives a particularly simple policy rule: the price on street should match the price off street (Corollary 1 ). We show that a simple time restriction, common in practice, induces excessive searching behaviour. Pricing instruments are thus more efficient, in this context, than this particular type of quantity instrument.

Our simple matching rule is shown to break down if the off-street market is not competitive. We examine the extreme case of a monopolistic off-street supplier. The optimal on-street price is a 'knife-edge' result: the price on-street is raised either until the off-street firm is just induced to undercut the on-street market but no further, or as high as possible without inducing the firm to undercut. Our numerical model suggests that, for plausible parameter values, either type of result may dominate. Our results hold for any convex search cost function. The crucial insight is that if prices are equal across markets, drivers do not incur positive search costs in equilibrium.

Certain caveats should be stressed. Firstly, we consider only a single monopolistic supplier of off-street space. This is sufficient to demonstrate that the 'matching' type of result breaks down. A more realistic model, however, would consider an oligopolistic market structure. This may have important consequences on the desirability (and possibility) of the on-street market being undercut.

Secondly, for simplicity, we assume identical consumers. The optimal centralised allocation and market allocation would differ in the presence of 
heterogeneous consumers. In particular, a common policy is to separate spatially long-term parking from short-term parking. Time restrictions act presumably as a crude means of preventing commuters using spots allocated to short-term parkers. The efficiency of such a policy remains to be investigated. However, we conjecture that the basic insight of this model, namely that simple-time restrictions induce excessive searching, will hold in a heterogeneous setting ${ }^{17}$, as will the essential trade-offs from raising price in the presence of a non-competitive off-street market.

Thirdly, we have not considered the interesting and pertinent issue of pricing parking space in the presence of underpriced road congestion. It would be useful to determine how different strategies for searching for a vacant spot (which route to choose, how much time to wait etc.) might interact with general traffic congestion on city centre streets and junctions. Different spatial patterns of parking pricing, for instance, might have very different impacts on congestion levels.

\footnotetext{
${ }^{17}$ A referee has pointed out a different argument in favour of time restrictions: if the government would like to help the poor, they might want to make parking free but restrict the length of stay i.e. rationing might be optimal (see Guesnerie and Roberts (1984)).
} 


\section{Notation}

\section{General}

$N$
$i \in\{X, Y\}$
$t_{i}, p_{i}$
$u, v$
$Q$
$C(t)$
$r$
$T$
$\lambda^{*}$
$\bar{\lambda}$
$\rho$
$S$
$D_{Y}$
$\varepsilon$
$W$

number of individuals

index for on- and off-street parking

length of stay and price per time unit

utility and consumer surplus from stay

supply of on-street peak period parking time

cost of supplying off-street parking time

maximum length of stay

length of stay at which marginal benefit equals zero

equilibrium fraction of drivers that search

fraction of drivers such that demand equals supply on-street

probability of finding a vacant on-street space

search cost

aggregate demand for off-street parking time

elasticity of parking time with respect to own price

social welfare

\section{Section 3}

$\lambda^{* *}, t_{i}^{* *}$

variables at optimal centralised value

Section 4

$p_{i}^{*}, t_{i}^{*}$

$F_{X}$

$p_{X}^{r}$

Section 5 variables at optimal decentralised value

total fee for parking on street

implicit on-street fee

monopoly price off-street

profit from undercutting/playing monopoly price respectively on-street price at which firm is indifferent between strategies best response function of the firm to a price on street. 


\section{Acknowledgements}

We are grateful to the editor and two anonymous referees for improving both the content and presentation of this paper. In addition, we would like to thank Bruno De Borger (Antwerp) and Bert Willems (K.U.Leuven) for providing extensive suggestions. Usual disclaimers apply. 


\section{References}

Anderson, S.P. and A. de Palma, 2004, The Economics of Pricing Parking, Journal of Urban Economics 55(1), 1-20.

Arnott, R., A. de Palma and R. Lindsey, 1991, A temporal and spatial equilibrium analysis of commuter parking, Journal of Public Economics 45, 301-335.

Arnott, R. and J. Rowse, 1999, Modeling Parking, Journal of Urban Economics 45(1), 97-124.

Axhausen, K., 1994, Parking demand and its characteristics, in: How to control mobility 6, les cahiers du Minstère Wallon de L’Équipment et des Transports.

Banister, D., 1990, Congestion: the market price for parking, Built Environment 15(13), 251-256.

Bös, D., 1985, Public sector pricing, in: A.J.Auerbach and M.Feldstein, eds., Handbook of public economics, Vol. 1 (North Holland, Amsterdam).

Calthrop, E., 2001, Essays in urban transport economics, Ph.D. thesis 151, Catholic University of Leuven, Belgium.

Calthrop, E. and S. Proost, 2002, Regulating on-street parking, ETE working paper 2002-02, CES, Catholic University of Leuven.

Calthrop, E., S. Proost and K. Van Dender, 2000, Parking policies and road pricing, Urban Studies 37(1), 63-76.

Dasgupta, P. and E. Maskin, 1986, The existence of equilibria in discontinuous economic games. 1.Theory, Review of Economic Studies 53, 1-26.

Davison, C. and R. Deneckere, 1986, Long-run competition in capacity, short-run competition in price and the cournot model, Rand Journal of Economics 17(3), 404-415.

De Vany, A., 1976, Uncertainty, waiting time and capacity utilization - a stochastic theory of product quality, Journal of Political Economy 84(3), 523-541.

De Vany, A. and T. Saving, 1977, Product quality, uncertainty and regulation - the trucking industry, American Economic Review 67(4), 583-594.

Elliot, J.R. and C.C. Wright, 1982, The Collapse of Parking Enforcement in Large Towns, Traffic Engineering and Control 304-310.

Glazer, A. and E. Niskanen, 1992, Parking fees and congestion, Regional Science and Urban Economics 22(1), 123-132. 
Grimmett, G. and D. Stirzaker, 2001, Probability and Random Processes, $3^{\text {rd }}$ edition, Oxford University Press, Oxford.

Guesnerie, R. and K. Roberts, 1984, Effective policy tools and quantity controls, Econometrica 52(1), 59-84.

Hudson, R.H.C, K. Shoarian-Sattari and P. Kompfner, 1993, Car parking in central London, Traffic Engineering and Control 34(1), 15-19.

Sundaram, R.K., 1996, A first course in optimization theory, Cambridge University Press, Cambridge.

Verhoef, E.T., P. Nijkamp and P. Rietveld, 1995, The economics of regulatory parking policies: The (im)possibilities of parking policies in traffic regulation, Transportation Research 29A(2), 141-156.

Vickrey, W., 1959, Statement to the Joint Committee on Washington DC metropolitan problems: Exhibit 53 - Economizing on curb parking space - a suggestion for a new approach to parking meters, reprinted in 1994 in Journal of Urban Economics 36, 42-65.

Young, W., 2000, Modeling Parking: in D.Hensher and K.J.Button, eds., Handbook of Transport Modelling, Vol. 1 (Oxford, Elsevier Science) 409-420. 


\section{Annex A: The centralised allocation problem}

The centralised allocation problem is given above as one of maximising equation (7) subject to constraints (8). The purpose of this annex is two-fold: firstly, to justify the restriction in the solution space used to search for an optimum, and, secondly, to prove the solution is a global maximum, as claimed.

Restricting the solution space

The government maximises social welfare, $\mathrm{W}$, using controls of the time parked on each market, $t_{i}$ and the proportion of consumers allocated to each market, $\lambda_{i}$

$$
W\left(\lambda_{X}, \lambda_{Y}, t_{X}, t_{Y}\right)=N\left[\lambda_{X} U\left(t_{X}\right)+\lambda_{Y} U\left(t_{Y}\right)\right]-C\left(N \lambda_{Y} t_{Y}\right)
$$

Simple calculations ${ }^{18}$ reveal that $\lambda_{Y}=1-\lambda_{X}$ : decreasing marginal utility of time parked implies that everyone should park for some time. Thus the maximand becomes

$$
W\left(\lambda, t_{X}, t_{Y}\right)=N\left[\lambda U\left(t_{X}\right)+[1-\lambda] U\left(t_{Y}\right)\right]-C\left(N[1-\lambda] t_{Y}\right)
$$

Furthermore, it is also clear from inspection that some demand must be allocated to the on-street market. If not, some demand can be reallocated from the off-street to the on-street market, saving positive supply costs. Hence $\lambda>0, t_{X}>0$.

The government maximisation problem reduces to maximising (22) subject to the following inequality constraints (each assigned a multiplier, $\gamma_{k}, \mathrm{k}=(1,2,3)$ )

\footnotetext{
${ }^{18}$ Assume $1-\lambda_{X}-\lambda_{Y}>0$ and $\lambda_{Y}, t_{Y}>0$. Holding $\lambda_{X}, t_{Y}$ and total off-street supply constant, welfare is improved by allowing a new driver to park for $t_{Y}$ units of time, although this requires existing offstreet users to park for a marginally shorter period. Similar conditions hold under all possible regions of the solution space.
} 


$$
\begin{gathered}
h_{1}=1-\lambda \geq 0, \\
h_{2}=t_{Y} \geq 0, \\
h_{3}=Q-\lambda t_{X} \geq 0 .
\end{gathered}
$$

The final step is to notice that if constraint $h_{1}$ binds, $t_{Y}$ drops from the objective function, and is thus indeterminate. If constraint $h_{1}$ is slack, however, $t_{Y}>0$ given the standard $u^{\prime}(0)>C^{\prime}(0)$ assumption. Thus, there is no loss in generality in assuming $t_{Y}>0$ and dropping constraint $h_{2}$.

Optimal Solution

We adopt a standard Kuhn-Tucker procedure to solve for the optimal points. However, this procedure is known to provide only necessary conditions to a local optimum when constraint qualification holds. However, following a standard procedure (e.g. Sundaram, 1996, Chapter 6), we identify the optimum by comparing the value of the solutions at all critical points. This is only valid when (i) a global optimum is known to exist, and (ii) when constraint qualification holds.

We first show that these two conditions are met in this problem. Firstly, notice that, without loss of generality, we can restrict the domain of $t_{i}$ to $0 \leq t_{i} \leq T$. It is then clear that the domain of the problem is compact. An appeal to the Weierstrass Theorem yields existence of a maximum.

To establish the second condition, we need to show that the rank of the matrix of derivatives of the effective constraints, evaluated at the optimal solution, equals the cardinality of the set of effective constraints. There are only three possible values for 
the set $h_{E}$ of effective constraints at the optimum, namely, $h_{E}=\left(h_{1}, h_{2}\right), h_{E}=h_{1}$ and $h_{E}=h_{2}$. (It is straightforward to show that $h_{E}$ does not contain the empty set).

If both constraints are effective, we have

$$
D h_{E}\left(\lambda^{*}, t_{X}^{*}\right)=\left[\begin{array}{cc}
-1 & 0 \\
-Q & -1
\end{array}\right]
$$

which is of full rank (i.e. matches the cardinality of the set). Constraint qualification holds in this case. It is straightforward to establish the same result under all possible values of the set $h_{E}$. Both conditions have been established.

We then turn to the maximisation problem. The Langrangean for this problem is:

$$
\begin{aligned}
L\left(t_{X}, t_{Y}, \lambda, \gamma_{1}, \gamma_{2}\right)= & N\left[\lambda U\left(t_{X}\right)+[1-\lambda] U\left(t_{Y}\right)\right] \\
& -C\left(N[1-\lambda] t_{Y}\right) \\
& +\gamma_{1}[1-\lambda] \\
& +\gamma_{2}\left[Q-\lambda t_{X}\right]
\end{aligned}
$$

which gives rise to the following set of 5 equations

$$
\begin{gathered}
\frac{\partial L}{\partial t_{X}}=N u^{\prime}\left(t_{X}\right)-\gamma_{2}=0 \\
\frac{\partial L}{\partial t_{Y}}=u^{\prime}\left(t_{Y}\right)-C^{\prime}\left(N[1-\lambda] t_{Y}\right)=0 \\
\frac{\partial L}{\partial \lambda}=N\left[u\left(t_{X}\right)-u\left(t_{Y}\right)\right]+C^{\prime}\left(N[1-\lambda] t_{Y}\right) N t_{Y} \\
-\gamma_{1}-t_{X} \gamma_{2}=0 \\
\gamma_{1} \geq 0, \quad 1-\lambda \geq 0, \quad \gamma_{1}[1-\lambda]=0 \\
\gamma_{2} \geq 0, \quad Q-\lambda t_{X} \geq 0, \quad \gamma_{2}\left[Q-\lambda t_{X}\right]=0
\end{gathered}
$$

We solve for the critical points of this system, under each of the possible values of the set $h_{E}$. We examine each case in turn. 
Case 1: $h_{E}=h_{1}$

Since only constraint $h_{1}$ holds with equality, we have $\lambda=1$ and $Q-t_{X}>0$, and, via the complementary slackness condition $(28), \gamma_{2}=0$. Substituting this into equation (24), implies that $t_{X}^{*}=T$. Condition (25) implies that $u^{\prime}\left(t_{Y}^{*}\right)=C^{\prime}(0)$, which, given our assumption that $C^{\prime}(0)>0$ implies that $t_{Y}^{*}<T$. Substituting into equation (26)

$$
N u(T)-N\left[u\left(t_{Y}^{*}\right)-u^{\prime}\left(t_{Y}^{*}\right) t_{Y}^{*}\right]=\gamma_{1}
$$

which implies that $\gamma_{1}>0$. Finally, for equation (28) to hold requires $Q>T$. This is the only critical point and thus optimal.

Case 2: $h_{E}=h_{2}$

Since only constraint $h_{2}$ holds with equality, we have $\lambda<1$ and $Q=\lambda t_{X}$, and, via the complementary slackness condition(27), $\gamma_{1}=0$. Substituting these results, plus equations (24) and (25) into (26) gives

$$
u\left(t_{X}\right)-u^{\prime}\left(t_{X}\right) t_{X}=u\left(t_{Y}\right)-u^{\prime}\left(t_{Y}\right) t_{Y}
$$

which implies that $t_{X}^{*}=t_{Y}^{*}$. To derive an expression for the optimal length of stay, substitute this result, plus $\lambda^{*}=Q / t_{X}^{*}$ into expression (25), giving

$$
u^{\prime}\left(t_{X}^{*}\right)=C^{\prime}\left(N\left[t_{X}^{*}-Q\right]\right)
$$

This is clearly only optimal when $t_{X}^{*}>Q$ or in other words, $u^{\prime}(Q) \geq C^{\prime}(0)$ - the marginal benefit of additional parking time on the off-street market exceeds the 
marginal cost. Again, this is the only critical point that solves this system and thus is optimal.

Case 3: $h_{E}=\left(h_{1}, h_{2}\right)$

Since both constraints holds with equality, we have $\lambda=1$ and $Q=t_{X}$.

Substituting these results into equations (24) and (25), and in turn into equation (26) gives

$$
N\left\{\left[u(Q)-u^{\prime}(Q) Q\right]-\left[u\left(t_{Y}^{*}\right)-u^{\prime}\left(t_{Y}^{*}\right) t_{Y}^{*}\right]\right\}=\gamma_{1}
$$

The left hand side is non-negative if $t_{Y}^{*} \leq Q$, which, on using equation (25) gives the condition $u^{\prime}(Q) \leq C^{\prime}(0)$. As in the other cases, this is the sole critical point and thus optimal. 


\section{Annex B: model calibration}

We assume quadratic utility such that the parking demand curve is given by $u^{\prime}(t)=\alpha-\beta t$ and constant returns to scale in the supply of parking time off street. The numerical model requires estimates of four parameters: $Q, \alpha, \beta$ and $C^{\prime}$, plus a search cost function $S$.

(i) Estimating $Q$

We assume 12,000 on-street parking spots in central London (Hudson et al. (1993) report approximately 11,000 spots for 1989, while Elliot and Wright (1982) estimate 14,000 spots). Taking a peak-period equal to 5 hours, this gives 60,000 hours of on-street parking supply time. Hudson et al. (1993) - Fig.2 - report approximately 60,000 parking acts, excluding parking at the workplace over the time period 07001200. Thus on-street supply equals parking demand (at a zero price) when each driver stays for 1 hour. Hence $Q=1$. However, to allow for uncertainty, we also investigate $Q=0.5$ and $Q=3$.

(ii) Estimating $\alpha$ and $\beta$

Hudson et al. (1993) - Fig. 5 - report that the average duration of stay in central London is 4 hours. No information is given on price. Given that some positive charges were in place for on-street parking, we assume that the average maximum stay (at zero price) equals the full length of the peak period, 5 hours. We assume that 
the marginal willingness to pay for the initial hour is $€ 40$. These assumptions imply $\alpha=40$ and $\beta=8$.

(iii) Estimating $C^{\prime}$

Banister (1990) - Table 3 - estimates the resource cost per hour for the City of London at $£ 5.15$ per hour. Using an exchange rate of $1.4 € / £$, this converts to approximately $€ 7$ per hour. Thus $C^{\prime}=7$. To allow for uncertainty, we also investigate upper and lower bounds: $C^{\prime}=3.5$ and $C^{\prime}=14$.

(iv) Search cost function $S$.

A review of the literature revealed few empirical estimates of search costs. One exception is Axhausen (1994). The average reported length of search for a vacant on-street spot is 10.9 minutes. The results relate to the U.K. city of Birmingham during a Saturday afternoon. Assuming time to be valued at $£ 10$ per hour, this suggests a search cost of approximately $€ 2.5$.

As discussed in the section 2.4 above (particularly footnote 7), stochastic queueing theory suggests a convex cost function (in $\lambda$ and $t_{X}$ ). We adopt the following functional form

$$
S(\rho)=k\left[e^{d \lambda(1-\rho)}-1\right]
$$

which has the desired properties. The function depends on two unknown parameters: $d$ and $k$. We 'calibrate' these parameters by assuming that two-thirds of drivers choose to search when the price of parking on street is equal to one-half of the resource cost of facility parking. This gives $k=0.1$ and $d=1.5$. Given the arbitrary 
nature of this procedure, we perform considerable sensitivity tests on these parameter values. 
FIGURES AND TABLES

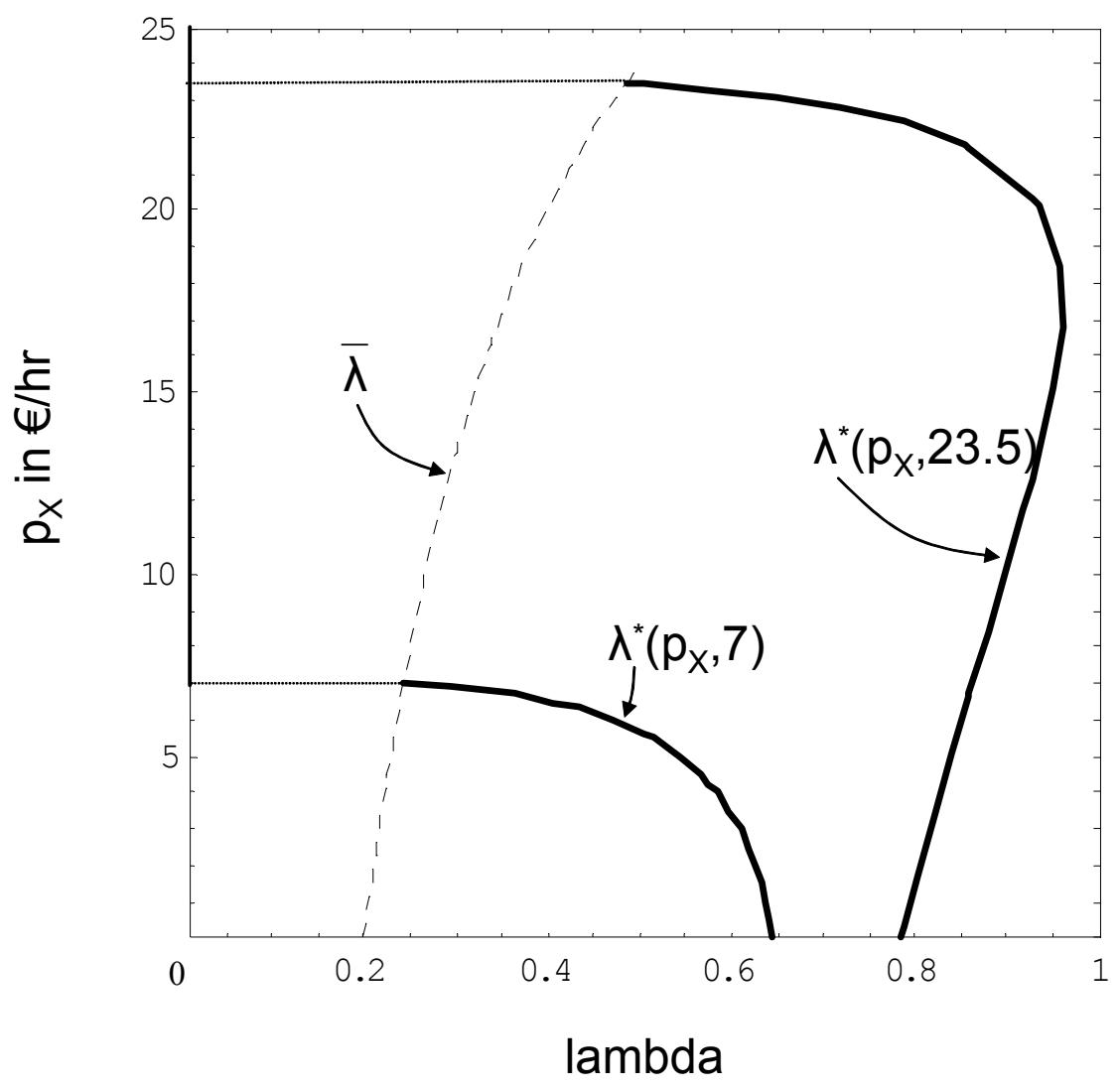

Figure 1 Equilibrium number of searchers 


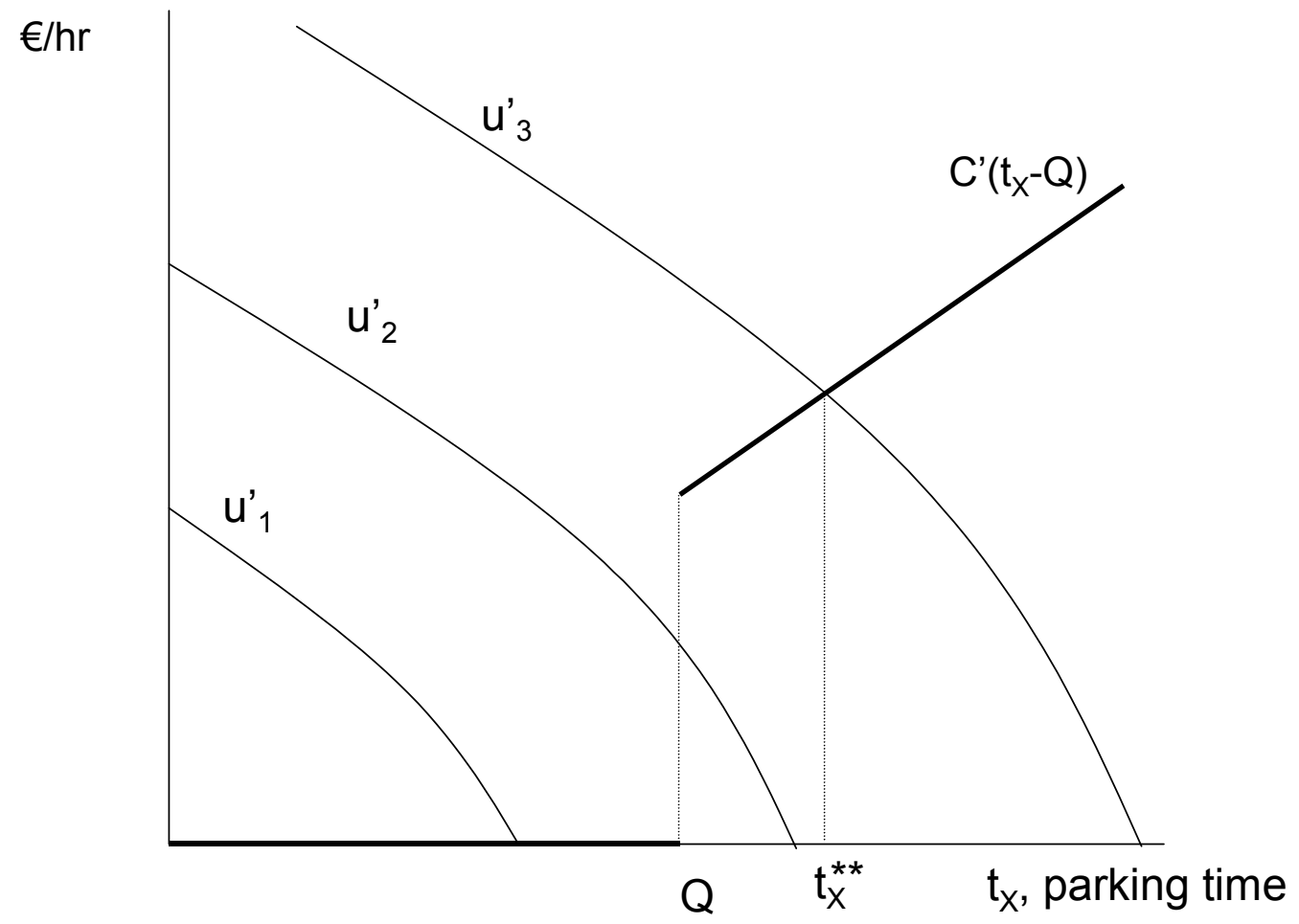

Figure 2 The allocation problem 
Table 1 Model results

\begin{tabular}{|c|c|c|}
\hline & symbol & $\begin{array}{l}\text { Value (in } \\
€ / \mathrm{hr} \text { ) }\end{array}$ \\
\hline \multirow[t]{2}{*}{ Parameters } & $Q$ & 1 \\
\hline & $C^{\prime}$ & 7 \\
\hline \multirow[t]{2}{*}{ Variables } & $p_{Y}^{m}$ & 23.5 \\
\hline & $I$ & 14.3 \\
\hline \multirow[t]{6}{*}{ Welfare } & $v(I)$ & 41.3 \\
\hline & $Q I$ & 14.3 \\
\hline & $v\left(p_{Y}^{m}\right)$ & 17.0 \\
\hline & $\Delta W$ & 10.0 \\
\hline & $W$ & 64.7 \\
\hline & $W_{F B}$ & 75.1 \\
\hline
\end{tabular}


Table 2 - Sensitivity tests

\begin{tabular}{|c|c|c|c|c|c|c|}
\hline & \multicolumn{5}{|c|}{ Scenarios } \\
\hline & & BMK & HI Q & LO Q & HI C' & LO C' \\
\hline \multirow[t]{2}{*}{ Parameters } & $Q$ & 1 & 3 & $0 . \overline{5}$ & 1 & 1 \\
\hline & $C^{\prime}$ & 7 & 7 & 7 & 15 & 3.5 \\
\hline \multirow[t]{2}{*}{ Variables } & $p_{Y}^{m}$ & 23.5 & 23.5 & 23.5 & 27.5 & 21.8 \\
\hline & $I$ & 14.3 & 9.0 & 16.7 & 19.6 & 12.0 \\
\hline \multirow[t]{6}{*}{ Welfare } & $v(I)$ & 41.3 & 60.1 & 34.0 & 25.9 & 49.0 \\
\hline & $Q I$ & 14.3 & 27.0 & 8.3 & 19.6 & 12.0 \\
\hline & $v\left(p_{Y}^{m}\right)$ & 17.0 & 17.0 & 17.0 & 9.8 & 20.8 \\
\hline & $\Delta W$ & 10.0 & 16.1 & 8.7 & -3.6 & 16.2 \\
\hline & $W$ & 64.7 & 67.8 & 62.2 & 41.3 & 78.8 \\
\hline & $W_{F B}$ & 75.1 & 89.0 & 71.6 & 54.1 & 86.7 \\
\hline
\end{tabular}


The Center for Economic Studies (CES) is the research division of the Department of Economics of the Katholieke Universiteit Leuven. The CES research department employs some 100 people. The division Energy, Transport \& Environment (ETE) currently consists of about 15 full time researchers. The general aim of ETE is to apply state of the art economic theory to current policy issues at the Flemish, Belgian and European level. An important asset of ETE is its extensive portfolio of numerical partial and general equilibrium models for the assessment of transport, energy and environmental policies.

\section{ETE WORKING PAPER SERIES 2004}

$N^{\circ} 2004-10$

$\mathrm{N}^{\circ} 2004-09$

N²004-08

N²004-07

N²004-06

$n^{\circ} 2004-05$

$n^{\circ} 2004-04$

$n^{\circ} 2004-03$

$n^{\circ} 2004-02$

$n^{\circ} 2004-01$
Calthrop E., Proost S. (2004), Regulating on-street parking

de Palma A., Proost S. (2004) Imperfect competition and congestion in the City

Pepermans G., Willems B. (2004), Ramsey Pricing in a Congested Network with Market Power in Generation: A Numerical Illustration for Belgium

Delhaye E. (2004), Traffic safety: speed limits, strict liability and a km tax

Eyckmans J., Finus M. (2004), An Empirical Assessment of Measures to Enhance the Success of Global Climate Treaties

Eyckmans J., Meynaerts E., Ochelen S. (2004), The Environmental Costing Model: a tool for more efficient environmental policymaking in Flanders

Saveyn B., Proost S. (2004), Environmental Tax Reform with Vertical Tax Externalities in a Federal State

Rousseau S. (2004), Timing of environmental inspections: Survival of the compliant

Knockaert J., Proost S., Van Regemorter D. (2004), Analysis of transport policy scenarios for EU-countries with PRIMEStransport

Franckx L., de Vries F.P. (2004), Environmental Liability and Organizational Structure

\section{ETE WORKING PAPER SERIES 2003}

Coenen G. (2003), Welfare maximizing emission permit allocations under constraints 